Consultant of: AbbVie, Boehringer Ingelheim, Celgene, Eli Lilly, Galapagos, Janssen, Novartis, Pfizer and UCB, Grant/research support from: AbbVie, Novartis, Pfizer and UCB, Robert G Lambert Consultant of: Parexel and Pfizer, Iris Eshed: None declared, Susanne Juhl Pedersen Speakers bureau: MSD, Pfizer, AbbVie, Novartis and UCB, Consultant of: AbbVie and Novartis, Grant/research support from: AbbVie, MSD, and Novartis, Maria Stoenoiu: None declared, Simon Krabbe: None declared, Paul Bird Speakers bureau: Janssen, Abbvie, UCB, Celgene, BMS, Novartis, Pfizer, Gilead, Eli-Lilly, Consultant of: Janssen, Abbvie, UCB, Celgene, BMS, Novartis, Pfizer, Gilead, Eli-Lilly, Violaine Foltz: None declared, Ashish Jacob Mathew: None declared, Frederique Gandjbakhch None declared, Joel Paschke: None declared, Philippe Carron Speakers bureau: Pfizer, MSD, Novartis, BMS, AbbVie, UCB, Eli Lilly, Gilead and Celgene, Consultant of: Pfizer, MSD, Novartis, BMS, AbbVie, UCB, Eli Lilly, Gilead and Celgene, Grant/research support from: UCB, MSD and Pfizer, Gabriele De Marco: None declared, Helena Marzo-Ortega Speakers bureau: AbbVie, Celgene, Janssen, Lilly, Novartis, Pfizer, Takeda and UCB, Grant/research support from: Janssen and Novartis, Anna Enevold Fløistrup Poulsen: None declared, Jacob L Jaremko: None declared, Philip G Conaghan Speakers bureau: AbbVie, AstraZeneca BMS, Eli Lilly, EMD Serono, Flexion Therapeutics, Galapagos, Gilead, Novartis, Pfizer and Stryker, Consultant of: AbbVie, AstraZeneca, BMS, Eli Lilly, EMD Serono, Flexion Therapeutics, Galapagos, Gilead, Novartis, Pfizer and Stryker, Mikkel Østergaard Speakers bureau: Abbvie, BMS, Boehringer-Ingelheim, Celgene, Eli-Lilly, Hospira, Janssen, Merck, Novartis, Pfizer, Regeneron, Roche, Sandoz, Sanofi and UCB, Consultant of: Abbvie, BMS, Boehringer-Ingelheim, Celgene, Eli-Lilly, Hospira, Janssen, Merck, Novartis, Pfizer, Regeneron, Roche, Sandoz Sanofi and UCB, Grant/research support from: Abbvie, BMS, Boehringer-Ingelheim, Celgene, Eli-Lilly, Hospira, Janssen, Merck, Novartis, Pfizer, Regeneron, Roche, Sandoz, Sanofi and UCB

DOI: 10.1136/annrheumdis-2021-eular.755

\section{OP0150 MODELLING IN INTERSTITIAL LUNG DISEASE ASSOCIATED WITH SYSTEMIC SCLEROSIS USING HIGH DIMENSIONAL IMAGE ANALYSIS}

M. Maciukiewicz ${ }^{1}$, J. Schniering ${ }^{1}$, H. Gabrys ${ }^{2}$, M. Brunner ${ }^{1}$, C. Blüthgen ${ }^{3}$, C. Meier ${ }^{1}$, M. Guckenberger ${ }^{2}$, H. Fretheim ${ }^{4}$, A. M. Hoffmann-Vold ${ }^{4}$, O. Distler ${ }^{1}$, T. Frauenfelder ${ }^{3}$, S. Tanadini-Lang ${ }^{2}$, B. Maurer ${ }^{1,5}{ }^{1}$ Center of Experimental Rheumatology, Department of Rheumatology, University of Zurich, Zurich, Switzerland; ${ }^{2}$ Department of Radiation Oncology, University Hospital

Zurich, University of Zurich, Zurich, Switzerland; ${ }^{3}$ Institute of Diagnostic and Interventional Radiology, University Hospital Zurich, University of Zurich, Zurich Switzerland; ${ }^{4}$ Institute of Clinical Medicine, University of Oslo, Rheumatology, Oslo University Hospital, Oslo, Norway; ${ }^{5}$ Department of Rheumatology and Immunology, University Hospital Bern, Bern, Switzerland

Background: The interstitial lung disease (ILD) associated with connective tissue diseases including systemic sclerosis (SSc) is heterogenous disease characterized by reduced survival of approximately 3 years (1). "Radiomics" is a field of research which describes the in-depth analysis of tissues by computational retrieval of high-dimensional quantitative features from medical images (2). Our previous study suggested capacity of radiomics features to differentiate between "high" and "low" risk groups for lung function decline in two independent cohorts (3)

Objectives:

- bTo develop robust, machine learning (ML) workflow for "radiomics" data in SSc-ILD to select optimal methods for prediction.

- oTo predict the time to individual lung function decline defined as defined by the time to a relative decline of $\geq 15 \%$ in Forced Vital Capacity (FVC) $\%$ as previously (3), using workflow.

Methods: We investigated two cohorts of SSc-ILD: 90 patients (76.7\% female, median age 57.5 years) from the University Hospital Zurich and 66 patients (75.8\% female, median age 61.0 years) from Oslo University Hospital's. Patients were retrospectively selected if (3): a) diagnosed with early/mild SSc according to the Very Early Diagnosis of Systemic Sclerosis (VEDOSS) criteria, b) presence of ILD on HRCT as determined by a senior radiologist. For every subject, we defined 1,355 robust radiomic features from HRCT images. The follow-up period was defined as the time interval between baseline visit and the last available follow-up visit.

We have developed a systematic computational workflow to build predictive $M L$ models. To reduce the number of redundant radiomic features, we applied correlation thresholds. We applied distinct methods including 1) Lasso Penalized Regression for feature selection, and 2) Random Forest (RF) for modeling using the R package 'caret'. To select the optimal ML model, we randomly divided derivation cohort into Training (70\%) and Holdout (30\%) sets and applied fivefold cross-validation ( $5 \mathrm{kCV}$ ) for feature and classifier selection on Training set only.

Results: We have investigated various methods to select the optimal set of predictive radiomic features. Since the $M L$ model performance is affected by both feature, and classifier selection, we assessed these factors first.

Results from feature filtering and selection, suggested that the combination of correlation threshold of 0.9 with Lasso regression proved best. As we perform feature selection in $5 \mathrm{k}$ CV workflow, features present in at least 2 sets entered model optimization step.

During model selection, we selected RF classifier. We detected positive correlation between actual and predicted values with Spearman's rho $=0.313, p=0.167$ and Spearman's rho $=0.341, \mathrm{p}=0.015$ in Oslo and Holdout sets respectively, as shown on Figure 1. The percentage of variance remained modest for both Holdout $(\mathrm{Rsq}=0.104)$ and Oslo $(\mathrm{Rsq}=0.126)$ datasets

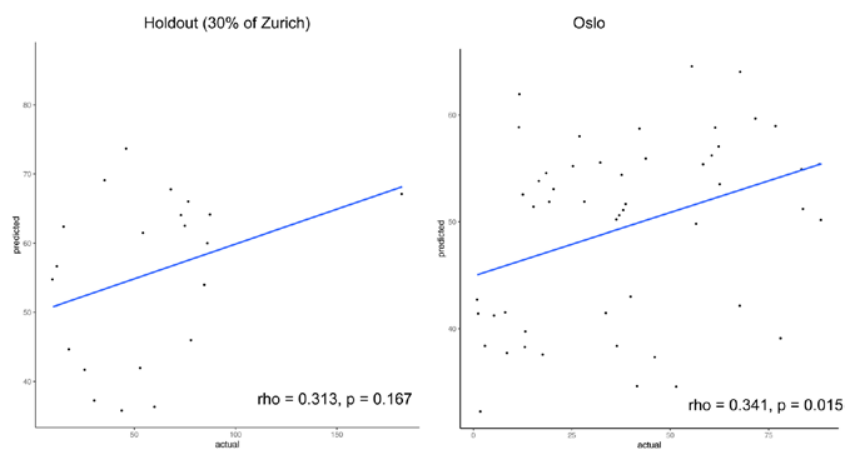

Figure 1. Performance of the best, RF classifier shown as scatterplot between actual and predicted values of individual time to lung decline.

Conclusion: In summary, we: (1) developed ML workflow that allowed to select o optimal methodology for modeling (i.e., feature and classifier selection), and (2) provide models that predicted time to individual lung function decline, characterized by significant correlation between predicted and actual values.

\section{REFERENCES:}

[1] Hansell DM, Goldin JG, King TE, Jr., Lynch DA, Richeldi L, Wells AU. CT staging and monitoring of fibrotic interstitial lung diseases in clinical practice and treatment trials: a position paper from the Fleischner Society. Lancet Respir Med. 2015;3(6):483-96.

[2] Lambin, P. et al. Radiomics: extracting more information from medical images using advanced feature analysis. Eur. J. Cancer 48, 441-446 (2012).

[3] Schniering J. et al. Resolving phenotypic and prognostic differences in interstitial lung disease related to systemic sclerosis by computed tomography-based radiomics. https://www.medrxiv.org/content/10.1101/2020.06.09.2 0124800v1

Disclosure of Interests: None declared

DOI: 10.1136/annrheumdis-2021-eular.2517 